\title{
Study on spatial-temporal distribution and environmental ties of Japanese B Encephalitis's mosquito vector as well as landing rate in The Olympic forest park
}

\section{Mei-De Liu ( $\sim 10338817 @ q q . c o m)$}

State Key Laboratory Of Pathogen And Biosecurity, Instuitute Of Microbiology And Epidemioloy https://orcid.org/0000-0001-9613-4772

\section{Yong Zhang}

Beijing Municipal Center for Disease Prevention and Control, Beijing Research Center for Preventive Medicine

\section{Ying Tong}

Beijing Municipal Center for Disease Prevention and Control, Beijing Research Center for Preventive Medicine

\section{Hong-Jiang Zhang}

Center for Disease and Prevention of Chaoyang District, Beijing

\section{Qiu-Hong Li}

Beijing Municipal Center for Disease Prevention and Control, Beijing Research Center for Preventive Medicine

\section{Ting Liu}

Beijing Municipal Center for Disease Prevention and Control, Beijing Research Center for Preventive Medicine

\section{Xiao-Jie Zhou}

Beijing Municipal Center for Disease Prevention and Control, Beijing Research Center for Preventive Medicine

\section{Xiao-Peng Zeng}

Beijing Municipal Center for Disease Prevention and Control, Beijing Research Center for Preventive Medicine

\section{Research}

Keywords: spatial-temporal distribution, environmental features, Japanese B Encephalitis, mosquito vector, landing rate

Posted Date: August 17th, 2020 
DOI: https://doi.org/10.21203/rs.3.rs-57343/v1

License: (c) (i) This work is licensed under a Creative Commons Attribution 4.0 International License. Read Full License 


\section{Abstract}

Background: Mosquito surveillance is crucial for understanding the epidemic potential, planning earlywarning, and effective control strategies. As a key public place in Beijing, the Beijing Olympic Forest Park (BOFP) makes serious epidemiological means for the Beijing, and the survey on the Japanese B Encephalitis (JBE) vector of Culex tritaeniorhynchus and mosquito landing in BOFP is crucial for the people living as well as JBE surveillance and control. It was hypothesized that the $C x$. tritaeniorhynchus could be trapped in a well-urbanization area of Beijing, and the distribution of $C x$. tritaeniorhynchus and mosquito landing rate are determined by the environmental factors.

Methods: Thus, this investigation was performed to understand the spatial-temporal distribution of $C x$. Tritaeniorhynchus and landing rate in BOFP, and the relationship between environmental features and densities of $C x$. tritaeniorhynchus as well as mosquito landing rate, considering the vector competent of $C x$. tritaeniorhynchus and important epidemiological means of BOFP in Beijing. From July to September, the $C x$. tritaeniorhynchus was trapped with $\mathrm{CDC}$-lights together with $\mathrm{CO} 2$ and the landing rate on the same sites as light traps were also investigated. What's more, the ties of environmental factors to the density of Cx. tritaeniorhynchus and landing rate was performed with SPSS, after the environmental factors datasets had been extracted with the $3 \mathrm{~S}$ procedures.

Results: As result showed, the highest density of $C x$. tritaeniorhynchus could be detected in September in the wetland environment, and the density was related to the grass-water in 400meters buffer (GW_400) and lower-trees in 100meter buffer distance (LT_100). For the landing rate investigation, the highest landing rates was observed in the wetland environment during September. In addition, there were two environmental features could be identified to correlate to landing rates; that is, grass-water in 400 meters buffer (GW_400) and high-trees in 100meter buffer distance (HT_100). It was concluded that the $C x$. tritaeniorhynchus, the vector of JBE, could be detected in BOFP (well-urbanization area), and the environmental factor could affect not only the spatial distribution of JBE vector but also the mosquito landing rates in BOFP.

Conclusions: The information achieved from this study could offer advice to people escaping from mosquito biting and provide useful information to prevent mosquito-borne diseases in Beijing, which means a lot to the public health of Beijing.

\section{Introduction}

Japanese B Encephalitis (JBE), one acute infectious disease transmitting through mosquito vector, pose a great risk to the health of people, special for the child[1]. The $C x$. tritaeniorhynchus is the major mosquito vector in China, its population density is major factor influencing the JBE in a special area [2]. In China, the larva $C x$. tritaeniorhynchus breeds majorly in a rice field and its' adult are always found in cattle shed[3], thus the $C x$. tritaeniorhynchus is always considered as rural mosquito species. In recent years, however, the $C x$. tritaeniorhynchus could be trapped in the urban area in China[4][5]. In the urban 
area of Beijing, the mosquito species that could be trapped generally include Culex pipiens pallens (vector for Bancroftian filariasis), Aedes albopictus (vector for Dengue fever). Therefore, the colonized of $C x$. tritaeniorhynchus in the urban area of the city start to catch the focus from vector-epidemiology of view. The mosquito landing rates are an influential parameter to provide accurate correlations between human and mosquito contacts[6]. It not only indicates the mosquito density, but also predicts the potential of mosquito-borne diseases break-out, in the term of the mosquito-borne epidemiology [7]. Thus, landing rates investigation plays a key role in protecting people from mosquito attack and prevention of mosquito-borne diseases [8].

After the Olympic Games in 2008, the Beijing Olympic Forest Park(BOFP) transform from Olympic facility to an ecological parkland. Firstly, it improves Beijing's situation of environment and climate, for the reason that the BOFP is the important buffer barrier for Beijing urban ecological system. Specially, the BOFP is of great significance to maintaining the structure of Beijing urban ecological system (the continuity, bio-diversity protecting, preserve of species and its habitats) and even urban ecological security. Secondly, the Olympic forest park is opened to the public for free and becomes Beijing's most famous park for tourism, leisure, entertainment, sport fitness, etc. From public health point of view, the BOFP could also be one key point as surveillance of mosquito vector as well as its transmitting disease in the context of urban environmental system.

The vector population is closed correlated to the environmental factor[9, 10], which providing the breeding for larva and resting for adults[11-13]. So, studying the correlation of environmental factor with mosquito population could provide corresponded measures for the vector prevention and control. What's more, investigating the landing rates under natural conditions, in various time scales and different environmental dimensions, can provide vital information for the guidance of mosquito control. Therefore, many studies have focused on mosquito landing rates, with regard to its temporal variation's characteristics[14, 15] and correlation with environment features [16, 17]. However, very few studies had described the trends of mosquito landing rates-being related to scales of spatial and time features, and there is no further research focusing on correlations between environmental features and mosquito abundance. Although some researchers had noticed the environmental influence on mosquito landing activity, they only focus on landing data on human, without further quantitative analyses on the association of environmental features to mosquito landing rates.

With the recent application advancement of 3S technology, especially RS-remote sensing and GISGeographic Information System, researchers are able to use these technologies for quantitative extraction of environmental features[11], conducting analyses of features with mosquito population indexes [18], and prevention of mosquito-borne disease[19]. That, the $3 \mathrm{~s}$ system had been used to study the correlation between environmental factor with malaria[20], dengue[21], WNV[22], and so on. Considering the advantage of the $3 \mathrm{~s}$ technology system, in this study, it was proceeding to study the correlation of the $C x$. tritaeniorhynchus population density, mosquito landing rate, and environmental factors. 
In present study, we took the BOFP as an experimental site to investigate the dynamic distribution patterns of JBE vector population, mosquito landing rates and ties to their surrounding environmental features. Taken the public health significance in accounted, studying here would benefit guarding against mosquito bites protection and mosquito-borne disease prevention, by the way of advising on escaping from mosquito biting for people as well as mosquito prevention for the BOFP. In addition, this paper could support on targeted ecological environmental reconstruction for mosquito prevention and prevent blindly ecological management with the vital significance of the ecological environment reserving in BOFP.

\section{Material And Method}

\section{Study area}

The Beijing Olympic forest park is the largest urban greening landscape in Asia, locating in of Chao-Yang district and covering an area of 680 hectares. The park is divided into south and north two gardens by fifth ring road of Beijing, and that two sub-parks are connected with one artificial simulation of the natural ecological corridor across city highway, which ensure the continuity of urban forest park ecological green space system and species diversity. This park, one of the important ecological barriers of Beijing, has important ecological strategic significance in quality improvement of urban environment and climate. Being one of the important public places of entertainment for people, studies on the spatial and temporal distribution of the mosquito vector in this area has important significance for reducing the crowd bitten probability and mosquito-borne diseases spreading probability.

\section{GPS: Trapping sites' design and location}

In the southern park, five areas were selected as experimental sites for measuring mosquito landing rates, including east (ease gate area with more trees), northeast (northern gate area of the forest besides the river), the wetland (western area with wetland), center island (center island surrounding by water) and south (south gate area with lawn). The coordinate information of five sites was provided with GPS using WV2 satellite remote sensing analyses.

\section{RS: Surface features classification in BOFP}

With remote sense packages in QGIS (QGIS.org (2020). QGIS Geographic Information System. Open Source Geospatial Foundation Project. http://qgis.org), the unsupervised ISODATA procedure was used to classify the surface features in BOFP basing on WV2 datasets. The surface features in BOFP could be identified as Residential Area(RA): human living environments, Open-Water(OW): water without any covering thing, High-Tree(HT): high trees like features, Low-Tree(LT): shrubs like vegetation, GrassWater(GW): water with covering vegetation or well irrigating vegetation, and Lawn Area (LA): area covered with lawn area. What's more, the NDVI (Normalized Difference Vegetation Index) and NDWI (Normalized Difference Water Index) raster datasets were also generated by remote sense analysis basing on WV2 satellite remote sensing data over the study area. 
As the GW feature was found corelated to the vector density as well as landing rate, the field checking on the GW feature was then performed to identify the exact landscapes in BOFP. To do so, thirty randomly selected position in GW remote sense catalogic image firstly. Secondly, field checking exactly landscape type each of them basing on the spatial position information.

\section{GIS: environmental spatial datasets surround trapping site}

Different distance(100 m, 200 m, 400 m, 600 m, 800 m, 1000m)buffer area around trapping sites were produced in the context of geographic information system(QGIS.org (2020). QGIS Geographic Information System. Open Source Geospatial Foundation Project. http://qgis.org). Using the spatial analysis method, environmental data from each buffer area was extracted and listed at Table 1, and environmental classification database was built simultaneously.

Table 1.

The environmental features that would be used in this paper

\begin{tabular}{|c|c|}
\hline Abbreviation of features & Geo-environmental sense \\
\hline AC_100, AC_200, AC_400, AC_600, & Artificial Construction's area within different buffer distance (100 \\
\hline AC_800, AC_1000, & m, $200 \mathrm{~m}, 400 \mathrm{~m}, 600 \mathrm{~m}, 800 \mathrm{~m}$ and $1000 \mathrm{~m})$ around surveillance site. \\
\hline OW_100, OW_200, OW_400, & Open Water's area within different buffer distance $(100 \mathrm{~m}, 200 \mathrm{~m}, 400$ \\
\hline OW_600,OW_800, W_1000, & $\mathrm{m}, 600 \mathrm{~m}, 800 \mathrm{~m}$ and $1000 \mathrm{~m}$ ) around surveillance site. \\
\hline HT_100, HT_200, HT_400, HT_600, & High Tree's area within different buffer distance $(100 \mathrm{~m}, 200 \mathrm{~m}, 400$ \\
\hline HT_800, HT_1000, & $\mathrm{m}, 600 \mathrm{~m}, 800 \mathrm{~m}$ and $1000 \mathrm{~m}$ ) around surveillance site. \\
\hline LP_100, LP_200, LP_400, LP_600, & Low Plant's area within different buffer distance $(100 \mathrm{~m}, 200 \mathrm{~m}, 400$ \\
\hline LP_800, LP_1000, & $\mathrm{m}, 600 \mathrm{~m}, 800 \mathrm{~m}$ and $1000 \mathrm{~m}$ ) around surveillance site. \\
\hline GW_100, GW_200, GW_400, GW_600, & Water with grass' area within different buffer distance $(100 \mathrm{~m}, 200 \mathrm{~m}$, \\
\hline GW_800, GW_1000, & $400 \mathrm{~m}, 600 \mathrm{~m}, 800 \mathrm{~m}$ and $1000 \mathrm{~m})$ around surveillance site. \\
\hline LA_100, LA_200, LA_400, LA_600, & lawn area's area within different buffer distance $(100 \mathrm{~m}, 200 \mathrm{~m}, 400 \mathrm{~m}$, \\
\hline LA_800, LA_1000, & $600 \mathrm{~m}, 800 \mathrm{~m}$ and $1000 \mathrm{~m}$ ) around surveillance site. \\
\hline NDVI_100, NDVI_200, NDVI_400, & Total NDVI values within different buffer distance $(100 \mathrm{~m}, 200 \mathrm{~m}, 400$ \\
\hline NDVI_600, NDVI_800, NDVI_1000, & $\mathrm{m}, 600 \mathrm{~m}, 800 \mathrm{~m}$ and $1000 \mathrm{~m}$ ) around surveillance site. \\
\hline NDWI_100, NDWI_200, NDWI_400, & Total NDWI values within different buffer distance $(100 \mathrm{~m}, 200 \mathrm{~m}, 400$ \\
\hline NDWI_600, NDWI_800, NDWI_1000, & $\mathrm{m}, 600 \mathrm{~m}, 800 \mathrm{~m}$ and $1000 \mathrm{~m}$ ) around surveillance site. \\
\hline
\end{tabular}

\section{Mosquito density survey with light trapping}


The study period started from July to September, and trapping was performed twice in each month. The peak of local mosquito density lies in both July and August, so the $\mathrm{CO}_{2}$-Trapping light was operated continuously during local mosquito density peak period. In these two months, trappings were done once every ten days period. The density of vector was calculated as counts/ (light hour), where the counts is the number of trapping vector, light is the number of light using for trapping, and the hour is the trapping time.

\section{Mosquito landing investigation}

The experiment of mosquito landing rates was initiated in July and ended in September. In each month, landing rates experiments were conducted twice a month, with one in the early of the month and the other nearly the end of the month. Each landing experiment lasted about fifteen minutes and was performed twice in one hour in which the mosquito biting peaks in Beijing. Randomly, five volunteers were chosen to perform the test at each site, and they were rotated in the following tests to avoid systematic errors, such as variations in mosquito attractiveness, density and site variation. Finally, the landing mosquito was caught and brought to the experimental room for morphological identification. The landing bite data was calculated as counts/(person-quarter), where the counts is the number of trapping mosquito, the person is the volunteer's number for trapping, and the quarter is the trapping time (fifteen minutes).

\section{Statistical correlation analysis of mosquito's density with environments}

Using SPSS19.0, regression analysis was performed to analyze the relationship of environmental variations with $C X$. tritaeniorhynchus density and mosquito landing rate. According to the AIC value together with the $P$ value, environmental factors relating to mosquito's density and landing rate were selected out and involved in regression analysis between the density and environmental features.

\section{Results}

\section{The density of $C x$. tritaeniorhynchus in each month of the total BOFP}

The Fig. 2. shown the distribution of $C x$. tritaeniorhynchus in each month in BOFP. During the trapping period, the density of vector mounted to the highest in September (11.2 mosquitoes per hour per light), and the density of the vector in July ( 0.35 mosquitoes per hour per light) and August ( 0.05 mosquitoes per hour per light) were smaller than 10 percent of that in September. As to predominance of $C x$. Tritaeniorhynchus, it also arrived at the peak in September (26.92\%), and the predominance of $C x$. tritaeniorhynchus in July (2.81\%) and August (1.12\%) were not more than the five percent of total mosquito community.

\section{The density of $C x$. tritaeniorhynchus in each site}

The Fig. 4 showed the vector density of each trapping site during each study month. There was no vector could be trapped in sites of east, northern-ease, center island, and southern in July and August; and only 
in September, the vector could be found in site east, northern-ease, center island, and southern. Both in July and August, the vector could only be trapped on site of wetland; and the density of the vector in September was the highest among all sites during each study month. Thus, the vector density and predominance spatial distribution pattern represented the same charters as that in total surveillance period. In the September, the Fig. 3 told us the density of the vector in each trapping position during the study period. The vector density in the wetland (13.58 mosquitoes per hour per light) was the highest among these trapping sites, and the vector density in east, northern-ease, and center island was 3.00 mosquitoes per hour per light, 4.25 mosquito per hour per light, and 10.00 mosquitoes per hour per light, respectively. Comparing to density distribution of $C x$. Tritaeniorhynchus, the predominance of vector mosquito in trap sites displayed different distribution pattern, the center island ranks (72.73\%) firstly among five sites following with north east (42.50\%), east (29.27\%) and wetland (16.15\%), expect for the zero in south site (no vector could be detected here). Specially, the predominance of vector in wetland ranked bottom although its density lies on the top among trap sites.

\section{Linear regression analysis of the density of the environmental factors}

The factors, showing significant correlation level with vector density, was then involved into the linear regression model in the stepwise method, in which the factor entered the final model if the probability of $F$ was smaller than 0.05 or was removed if the probability of $F$ was larger than 0.05 . In the end, the GW_400 and LT_100 was left and they could produce two linear regression models (Shown in Table 2). So, the finally linear regression model 2, as shown in Table 2, could be written in algebraic expression as:

Table 2

The relationship between environmental features vs mosquito vector density and landing rate

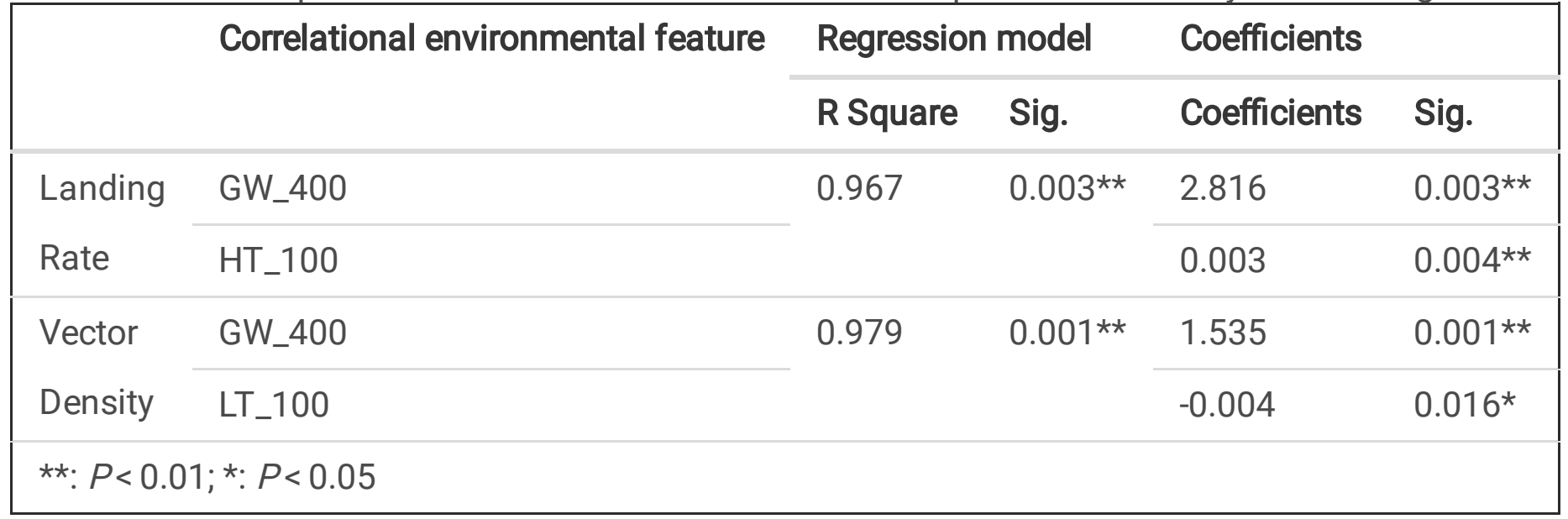

Where the $\mathrm{D}$ is the density of $C x$. tritaeniorhynchus, and the GW_400 and LT_100 are the summary acreage of grass-water and lower tress in 400 meters and 100meters buffer around the trapping sites, respectively. In the regression model, the GW_400 $(p=0.001<0.01)$, and LT_100 $(p=0.016<0.05)$ all showed significant linear relation with the density of $C x$. tritaeniorhynchus, where the GW_400 was positive and the LT_100 was a negative linear relation to the density of $C x$. tritaeniorhynchus.

Temporal dynamic of landing rates in different study positions in BOFP 
During total survey period, landing rates in 5 sites display spatial diversity, with the landing rates climax in September at the site of wetland, east, and center-land; the bottom landing rates could be seen in July in north-east, south, and east, and the bottom landing rates also could be seen in August in wetland and center land(Fig. 4). In north-east gate of BOFP, the landing rates in August and September were higher than those in July. In the Wetland area, the landing rates reach its height in September and climax through in surveillance period among all trapping sites. In the south gate area, the landing rates is generally lower than the other position (the landing rates were no more than 4), even at the highest in August. In the East gate location, the landing rates grew step by step from July to September and peaked in September. In the center point area (one center island in the lake), the landing rates in August hit the bottom level through surveillance period.

\section{Spatial dynamics of landing rates in each surveying month}

From July to September, the landing rates in BOFP shown different distribution pattern among sites in different month. What's more, peak landing rates site came out from wetland in July and September, the bottom landing rates could be seen twice in the south in July and September(Fig. 4). In July, the landing rates range from high to low in the following rank: wetland, central island, north-east gate, east gate, and south gate (Fig. 4). In August, the landing rates is highest in east gate location, and the landing rates here was higher than the highest point of the landing rates in July (at the wetland site); the landing rates in Wetlands was lower than that in July, even lower than that in the northeast gate. Mosquito landing rates in five sites ranked from high to low in the following sequence: the east gate - northeast gate- wetland south gate - Center Island (Fig. 4). In September, the landing rates, as that in July, peaked in wetlands again, and landing rates in this site were also peaked among all sites during the surveillance period. In addition, the landing rates in east gate site ranked second among all sites in September as well as in total surveillance period (Fig. 4).

\section{The correlation of landing rates to environmental features in BOFP}

The regression analysis results, on the relationship between environmental features and landing rates, was listed in Table 2. As the Table 2 shown, the $P$ values of $F$ testing on all regression models were less than 0.05 , which means the models could well predict the landing rates with environmental features respectively. Moreover, it was noticed from Table 2 that there were alternative environmental features being identified correlation with mosquito landing rates. That, landing rates was positive correlation to GW_400 (Coefficients $=2.816, P=0.003<0.01$ ), and landing rates was positive correlation to HT_100 (Coefficients $=0.003, P=0.004<0.01$ ). Also, the finally linear regression model, as shown in Table 2 , could be written in algebraic expression as:

\section{$H L D=3.2+2.816 * g w_{-} 400+0.003 * h t \_100$}

Where the HLD is the landing rate of mosquito, and the GW_400 and HT_100 are the summary acreage of grass-water and higher tress in the $\mathbf{4 0 0}$ meters and 100meters buffer around the trapping sites, respectively.

Field inspection on the GW environmental factors 
As results are shown above, the GW was correlative to both the density of $C x$. Tritaeniorhynchus and mosquito landing rate. In order to make ensures what exactly filed landscape the GW is, we also check 30 sites (Fig. 1) that was categorized as GW in RS analysis. As the results shown, these sites could be divided into four categories including well-irrigated grades (Fig. 5A, account for $43.33 \%$ ), regularly irrigating flower shrubs (Fig. 5B, account for 40\%), wetland covering with aquatic vegetation (Fig. 5C, account for $10 \%$ ), and Turf with water (Fig. 5D, account for $6.67 \%$ ).

\section{Discussion}

\section{Temporal distribution of $C x$. Tritaeniorhynchus and mosquito landing rate in BOFP}

Throughout the survey period, mosquito species display diversity temporal pattern in the different environmental site[23-25]. In Shanghai, for example, Xue [26]tell us that there is one early spring peak in April and another peak during August and September. On the context of BOFP, which locates in well urbanization area of Beijing, both the density and predominance peak of $C x$. tritaeniorhynchus could be seen in September, and there is only September peak. On the scale of Beijing city, September is not mosquito community density peak (should be in July or August). Thus, there is a temporal peak gap of density and landing rate between spatial scale of Beijing city and BOFP.

First of all, such peak departing my originate from spatial scale difference between Beijing city and BOFP, for the divergent climate or environmental factors. Second, the peak departing may also come from negative relationship between temperature and mosquito landing rates, as previous researches [27-29]. According to JBE surveillance in Beijing, the JBE case normally amounts to peak in late September[30]. From the viewpoint of mosquito-borne disease epidemiology, the coincidence of the vector density and landing rate in BOFP suggested that the risk of people in BOFP being bitted and infected with JVE must be biggest in September.

\section{Spatial distribution of JBE vector and mosquito landing rate in BOFP}

The spatial distribution of mosquito and landing rate is close related to the spatial position as well as the environmental feature around the positions $[16,17]$. In this study, the density of mosquito vector and landing rate in wetland spatial rank first among five sites (Fig. 3 and Fig. 4). The water, together with plants breeding in it, is good condition for high-density breeding of mosquito larva[31]. Particularly, the $C x$. tritaeniorhynchus is always bred in place that is water clear, slow flow, sunny hitting, and aquatic plants growing[3]. Here, the Wetland, with vegetation being ecological similar to typical breeding sites of $C x$. tritaeniorhynchus, might be a responsibility to high-density $C x$. tritaeniorhynchus in BOFP. Thus, high landing rates and mosquito vector density in a wetland accord well with mosquito ecology characters. On the contrary, with vegetation and water scarce, the southern gate site could only sustain for lower landing rates as well as mosquito breeding (the density of $C x$. tritaeniorhynchus was zero through total period). Except for the southern site, the predominance of $C x$. tritaeniorhynchus in wetland site was lower than those in other sites, which may result from the wetland is suited not only for the $C x$. tritaeniorhynchus but also for other mosquito species. People, in different environment, needs diversity prevention and control 
measures to achieve the best control results [32-34]. After 2008, the BOFP gradually became key site of tourism, leisure, entertainment, sport fitness, etc. Hence, understanding the spatial distribution pattern of vector and landing rate in BOFP could contribute to better guide on the crowd protection from mosquito biting or potential JBE rise. What's more, the spatial distribution results also can help the park administer reducing the blindness of insecticide usage, unnecessary use of pesticide, pesticide residue, and damage to the environment.

\section{Environmental factors tie to density of $C x$. tritaeniorhynchus and mosquito landing rate}

In general, the water body is an essential requirement for mosquito breeding, and the water with plantation (the water keeps good condition or weeds grow good environmental features) is the condition of the breed of mosquito with high larvae density[35, 36]. Also, it was demonstrated that the landing rates could be taken as important environment indication for mosquito breeding [37-39]. Therefore, both the landing rate and vector density were tied to the wetland in BOFP, and it also provide explain for the top density and landing rate in wetland sites, while the predominance in wetland rank end among five sites (except for the Sothern site). In BOFP, the wetland landscape provides good breeding condition not only for JBE vector but also for any other mosquito species. As to the low and high trees, it provide better rest site for adults mosquito[40], which may answer the question why the $C x$. tritaeniorhynchus density was a positive correlation with these two environmental factors in the present paper.

In addition, this paper not only pointed out the exact factor which could affection on the landing rate and vector density, but also showed the exact distance by which the environmental factor could affect them. After the emergence stage, the adult mosquito flies from its breeding sites to the rest site, which was restricted by the spatial distance relating to the mosquito species, environment, and climates[41]. In addition, mosquitoes' influence on humankind or other host was restricted in limited distance buffer around its larva sites [42,43]. Thus, the fly distance not only influences mosquitoes' harassment on humankind, but also lead to a diversity density, land rate, and infection rate of mosquito [44-46]. Identifying the buffer distance of environmental features affecting the landing rates illustrate the advantage of 3S technology on the analysis of environmental features with mosquito biting activity. Additionally, this study suggests a new point of view on mosquito behavioral science and contribute to decision on area extension of environmental management as well as chemical control.

\section{Afforest irrigation might also be causes for high mosquito density in BOFP}

As for field mosquito surveillance and environmental correlation analysis, the GW was tied to both the vector density and landing rate, and the density and landing rate in wetland (calculated as GW in remote sense analysis) rank first among study sites. Therefore, results here inform that the GW feature is key feature for the mosquito infestation in BOFP, and field checking on the GW feature in BOFP is necessary for mosquito and potential JBE risk management in BOFP. According to field checking, the GW feature in BOFP included four types: wetland with aquatic vegetation, well irrigated glades, regularly irrigating flower shrubs, and turf with water. For their stand water-body, the wetland with aquatic vegetation and turf with water are reasonably suitable for the mosquito breeding and corelated to the vector and landing rate. 
While for the well-irrigated glades and frequently watered flower shrubs, their ties to vector density landing rate may due to their regular irrigation producing lots of micro-niche for the mosquito larva breeding and supporting for the rest of mosquito adults. Based on the results of this study, objective environmental management could be conducted, when relevant environmental features were considered to be dealt within the comprehensive control system of integrating mosquito management. First, caution message could be declared in a particular area (wetland, for example) where high-density and landing rate are high, advising on mosquito-prevent medical materials application. Second, people also could intermittent irrigation of water with aquatic plants grow in it, and reduce the flooding of trees, flowers and trees by lowering the risk of mosquito breeding or perch measures in order to decrease the landing rates on people Finally, we could do the breeding sites control or residual spraying over special environmental factor, in order to decrease the density of vector and landing rate at the same time.

\section{Conclusion}

The survey of JBE case in Beijing showed that some JBE cases were local people living in the wellurbanization area[47], which means that JBE transmits not only in the countryside but in the downtown area. li[5] and Zhou [4] also found the $C x$. tritaeniorhynchus could be detected in the urban humanhabiting area, but they didn't identify the breeding site of the $C x$. tritaeniorhynchus and the environmental cause of the breeding in their paper. In present paper, however, the spatial-temporal distribution of vector and landing rate, and their ties to environmental features were identified by remote sensing and spatial analysis. From point of vector-borne disease epidemiology, the results obtained so far could provide some caution to us. First, the $C x$. tritaeniorhynchus was found breeding in well urbanization area of Beijing, which might lead to an epidemic of JBE in the hot-spot area of this city. Second, urban afforest irrigation may also produce function mosquitoes breeding sites that lead to augmenting of vector density, which should be paid full attention. Third, as wetland could provide good eco-system for mosquito breeding, it is necessary to figure out effective ways to prevent the breeding of mosquitoes in this type of features. What's more, the wetland protection was looked as the best selection for ecological recovering in Beijing[48], thus, present paper would also warn that the risk of public health issue ( $C x$. tritaeniorhynchus and JBE, for example) also should be considered, during city wetland recovering proceed. Finally, present paper, regarding temporal dynamic of mosquito vector and landing rates, could assist residents on how to select the activity time and position in BOFP in order to reduce the biting or disease infection risk.

\section{List Of Abbreviations}

The abbreviations used in the text are listed as Table 1. 
Table 1

The environmental features that would be used in this paper

\begin{tabular}{|c|c|}
\hline Abbreviation of features & Geo-environmental sense \\
\hline $\begin{array}{l}\text { AC_100, AC_200, AC_400, } \\
\text { AC_600, AC_800, AC_1000, }\end{array}$ & $\begin{array}{l}\text { Artificial Construction's area within different buffer distance } \\
(100 \mathrm{~m}, 200 \mathrm{~m}, 400 \mathrm{~m}, 600 \mathrm{~m}, 800 \mathrm{~m} \text { and } 1000 \mathrm{~m}) \text { around } \\
\text { surveillance site. }\end{array}$ \\
\hline $\begin{array}{l}\text { OW_100, OW_200, OW_400, } \\
\text { OW_600, OW_800, W_1000, }\end{array}$ & $\begin{array}{l}\text { Open Water's area within different buffer distance }(100 \mathrm{~m}, 200 \mathrm{~m} \text {, } \\
400 \mathrm{~m}, 600 \mathrm{~m}, 800 \mathrm{~m} \text { and } 1000 \mathrm{~m}) \text { around surveillance site. }\end{array}$ \\
\hline $\begin{array}{l}\text { HT_100, HT_200, HT_400, } \\
\text { HT_600, HT_800, HT_1000, }\end{array}$ & $\begin{array}{l}\text { High Tree's area within different buffer distance }(100 \mathrm{~m}, 200 \mathrm{~m} \text {, } \\
400 \mathrm{~m}, 600 \mathrm{~m}, 800 \mathrm{~m} \text { and } 1000 \mathrm{~m}) \text { around surveillance site. }\end{array}$ \\
\hline $\begin{array}{l}\text { LP_100, LP_200, LP_400, } \\
\text { LP_600, LP_800, LP_1000, }\end{array}$ & $\begin{array}{l}\text { Low Plant's area within different buffer distance }(100 \mathrm{~m}, 200 \mathrm{~m} \text {, } \\
400 \mathrm{~m}, 600 \mathrm{~m}, 800 \mathrm{~m} \text { and } 1000 \mathrm{~m}) \text { around surveillance site. }\end{array}$ \\
\hline $\begin{array}{l}\text { GW_100, GW_200, GW_400, } \\
\text { GW_600, GW_800, GW_1000, }\end{array}$ & $\begin{array}{l}\text { Water with grass' area within different buffer distance }(100 \mathrm{~m} \text {, } \\
200 \mathrm{~m}, 400 \mathrm{~m}, 600 \mathrm{~m}, 800 \mathrm{~m} \text { and } 1000 \mathrm{~m}) \text { around surveillance } \\
\text { site. }\end{array}$ \\
\hline $\begin{array}{l}\text { LA_100, LA_200, LA_400, } \\
\text { LA_600, LA_800, LA_1000, }\end{array}$ & $\begin{array}{l}\text { lawn area's area within different buffer distance }(100 \mathrm{~m}, 200 \mathrm{~m} \text {, } \\
400 \mathrm{~m}, 600 \mathrm{~m}, 800 \mathrm{~m} \text { and } 1000 \mathrm{~m}) \text { around surveillance site. }\end{array}$ \\
\hline $\begin{array}{l}\text { NDVI_100, NDVI_200, NDVI_400, } \\
\text { NDVI_600, NDVI_800, } \\
\text { NDVI_1000, }\end{array}$ & $\begin{array}{l}\text { Total NDVI values within different buffer distance }(100 \mathrm{~m}, 200 \mathrm{~m} \text {, } \\
400 \mathrm{~m}, 600 \mathrm{~m}, 800 \mathrm{~m} \text { and } 1000 \mathrm{~m}) \text { around surveillance site. }\end{array}$ \\
\hline $\begin{array}{l}\text { NDWI_100, NDWI_200, } \\
\text { NDWI_400, NDWI_600, } \\
\text { NDWI_800, NDWI_1000, }\end{array}$ & $\begin{array}{l}\text { Total NDWI values within different buffer distance }(100 \mathrm{~m}, 200 \mathrm{~m} \text {, } \\
400 \mathrm{~m}, 600 \mathrm{~m}, 800 \mathrm{~m} \text { and } 1000 \mathrm{~m}) \text { around surveillance site. }\end{array}$ \\
\hline
\end{tabular}

\section{Declarations}

\section{Ethics approval and consent to participate}

Not applicable

\section{Consent for publication}

Not applicable

\section{Availability of data and materials}

The datasets used and/or analyzed during the current study are available from the corresponding author on reasonable request.

\section{Competing interests}

The authors declare that they have no competing interests

\section{Funding}


This work was supported by grants from the Beijing Municipal Natural Science Foundation (7132038), the Cultivation Fund of Beijing Municipal Center for Disease Prevention and Control, Beijing Research Center for Preventive Medicine (2016-BJYJ-08), and the National Natural Science Foundation of China (81072349).

\section{Authors' contributions}

MEI-DE LIU and YONG ZHANG analyzed and interpreted the field data regarding mosquito and environmental features, and was the major contributor in writing the manuscript. YING TONG and HONGJIANG ZHANG identified the mosquito caught in the BOFP and analyzed the field data of the mosquitoes. QIU-HONG Li, TING Liu, and XIAO-JIE Zhou performed the mosquito trapping and field landscape investigation. XIAO-PENG ZENG designed study, planed the field works, and directed the study procedures. All authors read and approved the final version of the manuscript.

\section{Acknowledgments}

Not applicable

\section{References}

1. Chin R, Torresi J: Japanese B Encephalitis: An Overview of the Disease and Use of Chimerivax-JE as a Preventative Vaccine. Infect Dis Ther 2013, 2(2):145-158.

2. Olson JG, Ksiazek TG, Tan R, Atmosoedjono S, Lee VH, Converse JD: Correlation of population indices of female Culex tritaeniorhynchus with Japanese encephalitis viral activity in Kapuk, Indonesia. Southeast Asian J Trop Med Public Health 1985, 16(2):337-342.

3. Shuyuan Z: Advances in ecological and prevention research on Culex tritaeniorhynchus(National Cooperative Group from 1979 to 1984). Journal of Medical Pest Control 1986(03):50-58.

4. Ming-hao Z: Study on the urban mosquitoes integrated management:: Academy of Military Medical Sciences; 2008.

5. Li C, Xiao-xia G, En-jiong H, Yan-de D, Tong-yan Z: New breeding of Culex tritaeniorhynchus in city. Chinese Journal of Vector Biology and Control 2007, 18(1):31.

6. Hamer GL, Chaves LF, Anderson TK, Kitron UD, Brawn JD, Ruiz MO, Loss SR, Walker ED, Goldberg TL: Fine-scale variation in vector host use and force of infection drive localized patterns of West Nile virus transmission. PLOS ONE 2011, 6(8):e23767.

7. Jaleta KT, Hill SR, Seyoum E, Balkew M, Gebre-Michael T, Ignell R, Tekie H: Agro-ecosystems impact malaria prevalence: large-scale irrigation drives vector population in western Ethiopia. Malar J 2013, 12:350.

8. Wallace DI, Southworth BS, Shi X, Chipman JW, Githeko AK: A comparison of five malaria transmission models: benchmark tests and implications for disease control. Malar J 2014, 13:268. 
9. Calzolari M, Pautasso A, Montarsi F, Albieri A, Bellini R, Bonilauri P, Defilippo F, Lelli D, Moreno A, Chiari $\mathrm{M}$ et al: West Nile Virus Surveillance in 2013 via Mosquito Screening in Northern Italy and the Influence of Weather on Virus Circulation. PLOS ONE 2015, 10(10):e140915.

10. Garzon MJ, Jensen O, Schweigmann N: Environmental factors related to the abundance and activity of Ochlerotatus albifasciatus (Diptera: Culicidae) in an agricultural landscape of steppe arid climate. J MED ENTOMOL 2014, 51(4):733-741.

11. Arjunan NK, Kadarkarai M, Kumar S, Pari M, Thiyagarajan N, Vincent CT, Barnard DR: Factors influencing the spatial distribution of Anopheles larvae in Coimbatore District, Tamil Nadu, India. ACTA TROP 2015, 152:121-130.

12. Mangudo C, Aparicio JP, Gleiser RM: Tree holes as larval habitats for Aedes aegypti in urban, suburban and forest habitats in a dengue affected area. Bull Entomol Res 2015, 105(6):679-684.

13. Medeiros-Sousa AR, Ceretti-Junior W, de Carvalho GC, Nardi MS, Araujo AB, Vendrami DP, Marrelli MT: Diversity and abundance of mosquitoes (Diptera:Culicidae) in an urban park: Larval habitats and temporal variation. ACTA TROP 2015, 150:200-209.

14. Qiang G, Yi-bin Z, Pei-en L, Zhi-wei D, Kang X, Jian F, Hui C: Seasonal variance of mosquito density in different micro-environments and circadian periods. Chinese Journal of Hygienic Insecticides \& Equipments 2014(06):520-523.

15. Ren Z, Wang D, Hwang J, Bennett A, Sturrock HJ, Ma A, Huang J, Xia Z, Feng X, Wang J: Spatialtemporal variation and primary ecological drivers of Anopheles sinensis human biting rates in malaria epidemic-prone regions of China. PLOS ONE 2015, 10(1):e116932.

16. Cummins B, Cortez R, Foppa IM, Walbeck J, Hyman JM: A spatial model of mosquito host-seeking behavior. PLOS COMPUT BIOL 2012, 8(5):e1002500.

17. Qiang G, Yi-bin Z, Pei-en L, Zhi-wei D, Kang X, Jian K, Hui C: Community composition of mosquitoes in different enviroments and periods. Chinese Journal of Hygienic Insecticides \& Equipments 2014(05):424-427.

18. Regis LN, Acioli RV, Silveira JJ, Melo-Santos MA, Souza WV, Ribeiro CM, Da SJ, Monteiro AM, Oliveira $\mathrm{CM}$, Barbosa RM et al: Sustained reduction of the dengue vector population resulting from an integrated control strategy applied in two Brazilian cities. PLOS ONE 2013, 8(7):e67682.

19. Espinosa M, Weinberg D, Rotela CH, Polop F, Abril M, Scavuzzo CM: Temporal Dynamics and Spatial Patterns of Aedes aegypti Breeding Sites, in the Context of a Dengue Control Program in Tartagal (Salta Province, Argentina). PLoS Negl Trop Dis 2016, 10(5):e4621.

20. Moiroux N, Bio-Bangana AS, Djenontin A, Chandre F, Corbel V, Guis H: Modelling the risk of being bitten by malaria vectors in a vector control area in southern Benin, west Africa. Parasit Vectors 2013, 6:71.

21. Attaway DF, Jacobsen KH, Falconer A, Manca G, Waters NM: Risk analysis for dengue suitability in Africa using the ArcGIS predictive analysis tools (PA tools). ACTA TROP 2016, 158:248-257.

22. Valiakos G, Papaspyropoulos K, Giannakopoulos A, Birtsas P, Tsiodras S, Hutchings MR, Spyrou V, Pervanidou D, Athanasiou LV, Papadopoulos N et al: Use of wild bird surveillance, human case data 
and GIS spatial analysis for predicting spatial distributions of West Nile virus in Greece. PLOS ONE 2014, 9(5):e96935.

23. Mei-de L, Xue-zhong W, Tong-yan Z, Du Zhun-wei, Yan-de D, Jiu-shen L, Li-hua Z, Bao-lin L: Dynamics of Culex tritaeniorhynchus and Culex pseudovishnui populations in newly built and present villages in southern Yunnan Province. Chinese Journal of Ecology 2007, 26(11):1890-1893.

24. Kipyab PC, Khaemba BM, Mwangangi JM, Mbogo CM: The physicochemical and environmental factors affecting the distribution of Anopheles merus along the Kenyan coast. Parasit Vectors 2015, 8:221.

25. Yee DA, Abuzeineh AA, Ezeakacha NF, Schelble SS, Glasgow WC, Flanagan SD, Skiff JJ, Reeves A, Kuehn K: Mosquito Larvae in Tires from Mississippi, United States: The Efficacy of Abiotic and Biotic Parameters in Predicting Spatial and Temporal Patterns of Mosquito Populations and Communities. J MED ENTOMOL 2015, 52(3):394-407.

26. Rui-de X, Xiang-shi K, Bao-lin L: Study on the early occurrences and age-compositions of the overwintered mesquite, Culex tritaeniorhynchus Giles. Chinese Journal of Vector Biology and Control 1991, 2(2):65-69.

27. Smith $\mathrm{DL}$, Dushoff $\mathrm{J}$, McKenzie FE: The risk of a mosquito-borne infection in a heterogeneous environment. PLOS BIOL 2004, 2(11):e368.

28. Gui-lin Z, Bin L, Zeng-xian H, Rong-li D: The correlation analysis among the biting cycles,the population quantity of Aedes vexans and meteorological factors at Beiwan frontiers,Xinjiang province. Chinese Journal of Vector Biology and Control 2006(05):356-358.

29. Aniedu I: Dynamics of malaria transmission near two permanent breeding sites in Baringo district, Kenya. INDIAN J MED RES 1997, 105:206-211.

30. Wenyan J, Meiping S, Yang Z, Herun Z: Epidemiological Characteristics of Japanese Encephalitis B in Beijing,2000-2007. CHINA PREVENTIVE MEDICINE 2008, 9(12):1070-1072.

31. Govoetchan R, Gnanguenon V, Ogouwale E, Oke-Agbo F, Azondekon R, Sovi A, Attolou R, Badirou K, Youssouf RA, Osse R et al: Dry season refugia for anopheline larvae and mapping of the seasonal distribution in mosquito larval habitats in Kandi, northeastern Benin. Parasit Vectors 2014, 7:137.

32. N. Sogoba PVMM: Geospatial Health - The spatial distribution of iAnopheles gambiae sensu stricto-i and iAn_arabiensis-i (Diptera Culicidae) in Mali. Geospatial Health 2007, 1(2):213-222.

33. Prosper $\mathrm{O}$, Ruktanonchai $\mathrm{N}$, Martcheva M: Assessing the role of spatial heterogeneity and human movement in malaria dynamics and control. J THEOR BIOL 2012, 303:1-14.

34. Jing-li L, Yu-hong G, Xiao-bo L, Guang-chao Z, Jing-yi J, Qi-yong L: Study on the landing height of wintering Culex pipens pallens in Yongcheng city, Henan province, China. Chines Journal of Vector Biology and Control 2012(01):61-63.

35. Jacups SP, Kurucz N, Whelan PI, Carter JM: A comparison of Aedes vigilax larval population densities and associated vegetation categories in a coastal wetland, Northern Territory, Australia. J VECTOR ECOL 2009, 34(2):311-316. 
36. Kurucz N, Whelan PI, Carter JM, Jacups SP: A geospatial evaluation of Aedes vigilax larval control efforts across a coastal wetland, Northern Territory, Australia. J VECTOR ECOL 2009, 34(2):317-323.

37. Fondjo E, Robert V, Le Goff G, Toto JC, Carnevale P: [Urban malaria in Yaounde (Cameroon). 2. Entomologic study in 2 suburban districts]. Bull Soc Pathol Exot 1992, 85(1):57-63.

38. Kigadye ES, Nkwengulila G, Magesa SM, Abdulla S: Spatial variability in the density, distribution and vectorial capacity of anopheline species in Rufiji district, south-eastern Tanzania. Tanzan J Health Res 2011, 13(4):112-118.

39. Zhu L, Qualls WA, Marshall JM, Arheart KL, DeAngelis DL, McManus JW, Traore SF, Doumbia S, Schlein Y, Muller GC et al: A spatial individual-based model predicting a great impact of copious sugar sources and resting sites on survival of Anopheles gambiae and malaria parasite transmission. Malar J 2015, 14:59.

40. Muturi EJ, Gardner AM, Bara JJ: Impact of an Alien Invasive Shrub on Ecology of Native and Alien Invasive Mosquito Species (Diptera: Culicidae). ENVIRON ENTOMOL 2015, 44(5):1308-1315.

41. Sellers RF: Weather, host and vector-their interplay in the spread of insect-borne animal virus diseases. J Hyg (Lond) 1980, 85(1):65-102.

42. Landau KI, van Leeuwen WJ: Fine scale spatial urban land cover factors associated with adult mosquito abundance and risk in Tucson, Arizona. J VECTOR ECOL 2012, 37(2):407-418.

43. Cailly P, Balenghien T, Ezanno P, Fontenille D, Toty C, Tran A: Role of the repartition of wetland breeding sites on the spatial distribution of Anopheles and Culex, human disease vectors in southern France. Parasit Vectors 2011, 4:65.

44. Rezza G: Dengue and chikungunya: long-distance spread and outbreaks in naive areas. PATHOG GLOB HEALTH 2014, 108(8):349-355.

45. Barros FS, Honorio NA: Deforestation and Malaria on the Amazon Frontier: Larval Clustering of Anopheles darlingi (Diptera: Culicidae) Determines Focal Distribution of Malaria. AM J TROP MED HYG 2015, 93(5):939-953.

46. Nixon CP, Nixon CE, Arsyad DS, Chand K, Yudhaputri FA, Sumarto W, Wangsamuda S, Asih PB, Marantina SS, Wahid I et al: Distance to Anopheles sundaicus larval habitats dominant among risk factors for parasitemia in meso-endemic Southwest Sumba, Indonesia. PATHOG GLOB HEALTH 2014, 108(8):369-380.

47. Ce C, Yan Z, Jing S: Analysis on Epidemic Situation of Legal Infectious Diseases in Xicheng District. Journal of Preventive Medicine 2018, 30(1):89-90, 93.

48. Hong-jiang Z, Jun-qi G, Cheng-jun T, Zheng Z, Mei-de L, Yong Z: Distribution and seasonality of Culex tritaeniorhynchus in Chaoyang district,Beijing. Chinese Journal of Vector Biology and Control 2016, 27(2):148-150.

\section{Figures}




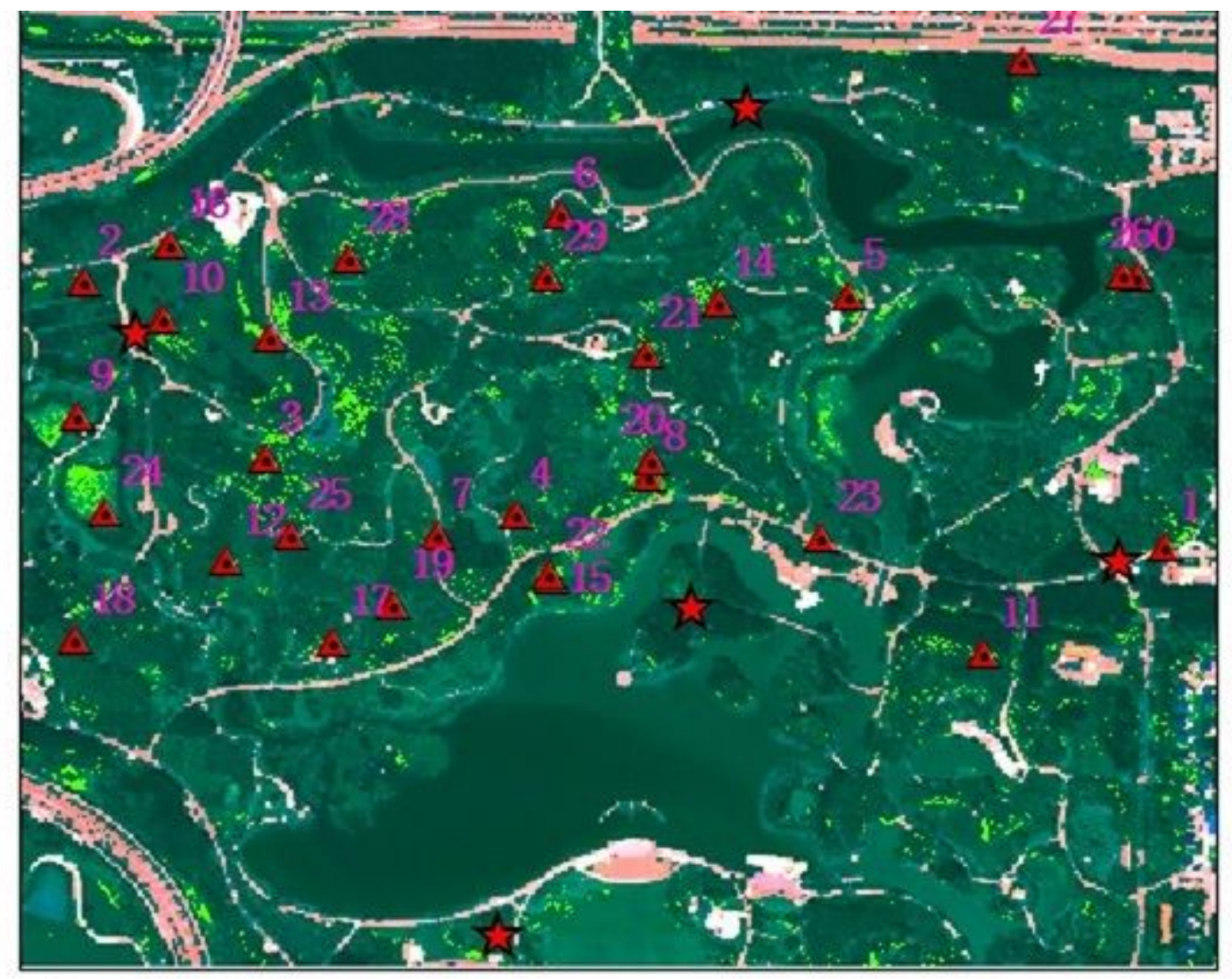

Legend

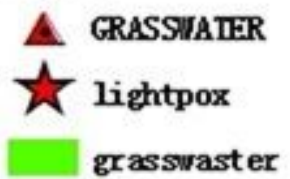

Figure 1

Map of trap sites and grass-water (GW) landscape in the study area. 

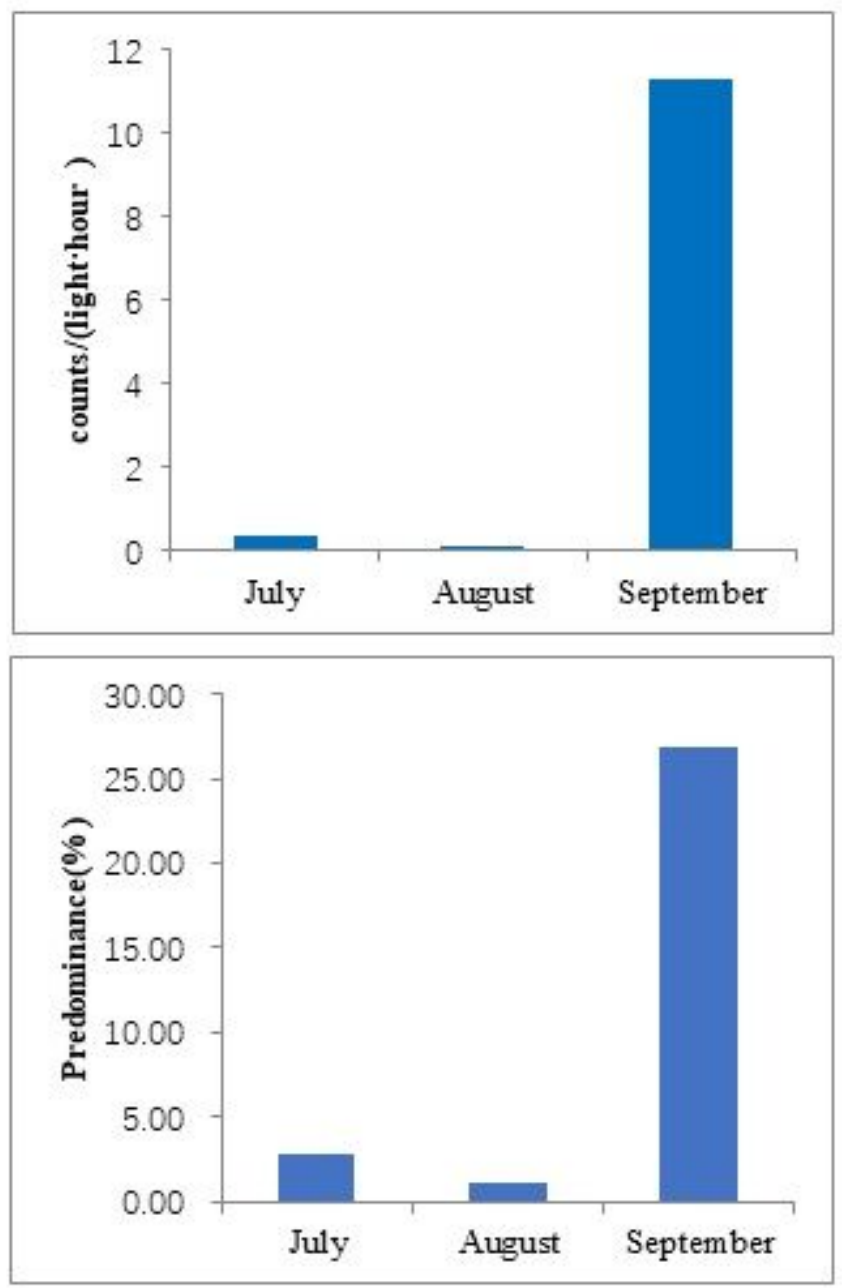

Figure 2

Density of Cx. tritaeniorhynchus in each month of the total BOFP. 

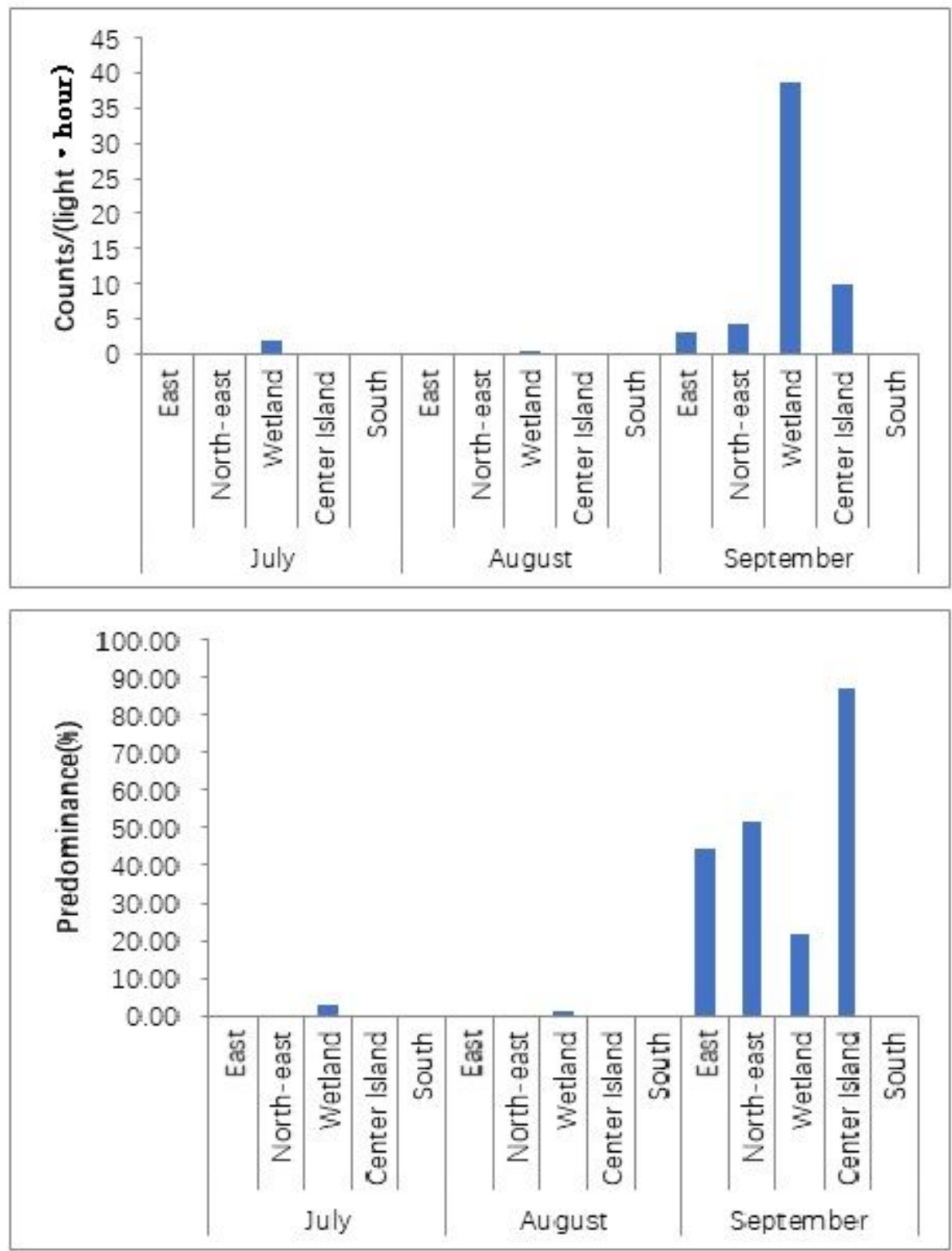

Figure 3

Density of Cx. tritaeniorhynchus at each site during three survey months (July, August, September). 


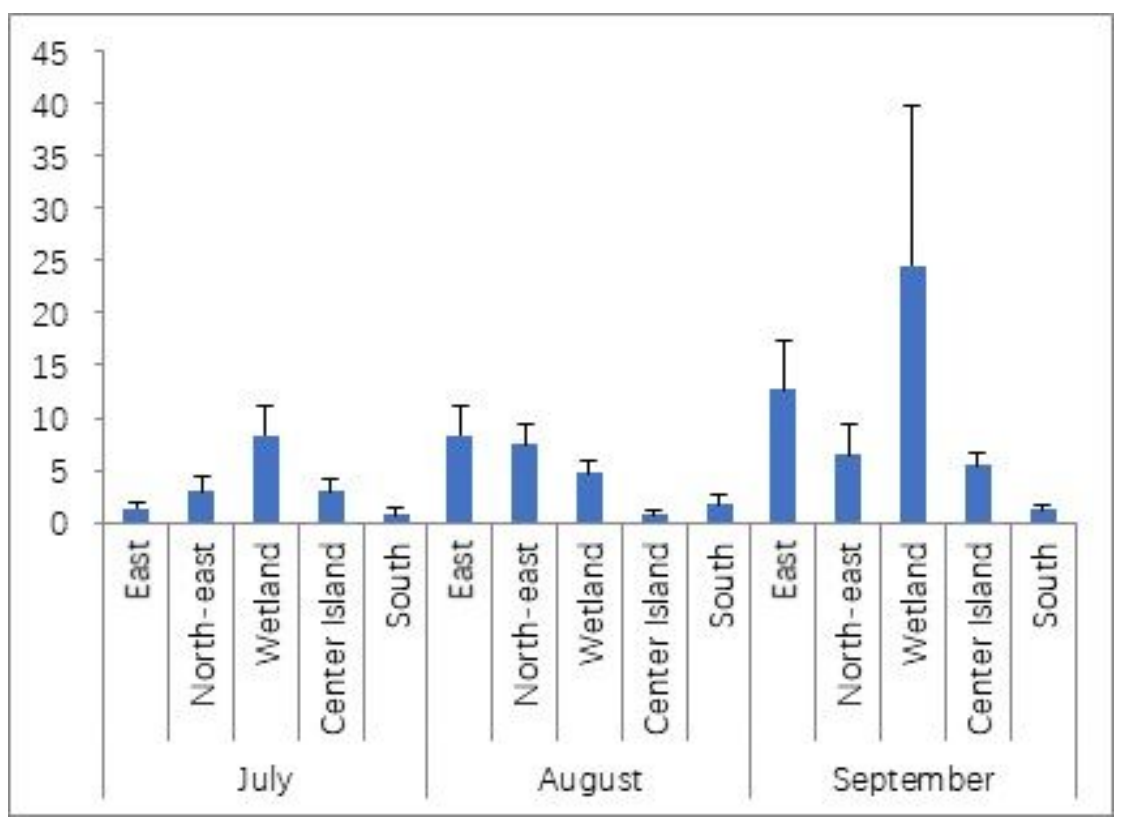

Figure 4

Mosquito landing rates at five sites from July to September.

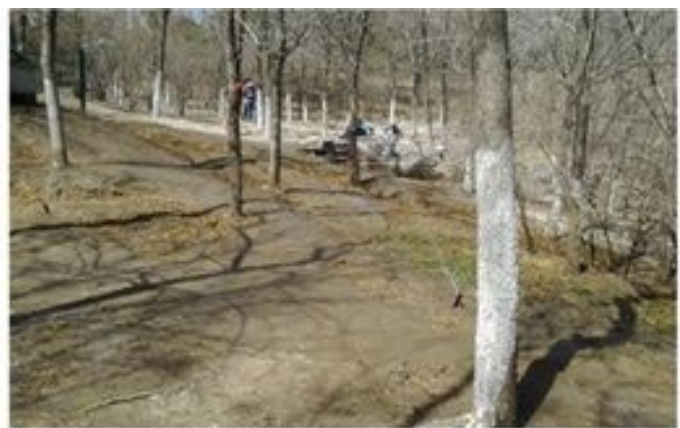

A: Well irrigated glades

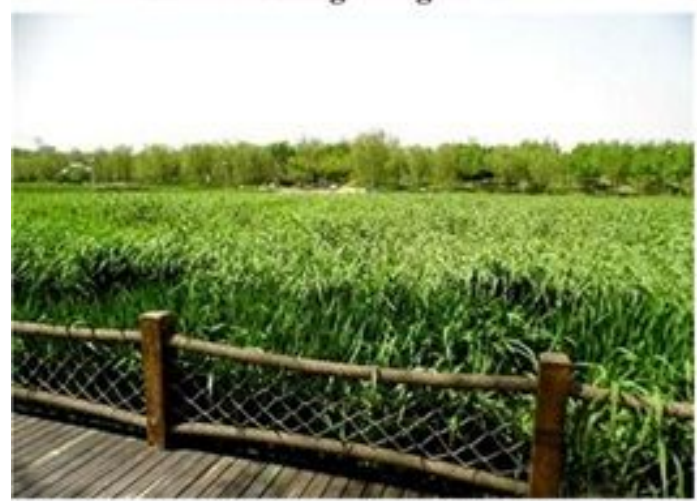

C: Wetland covering with aquatic vegetation

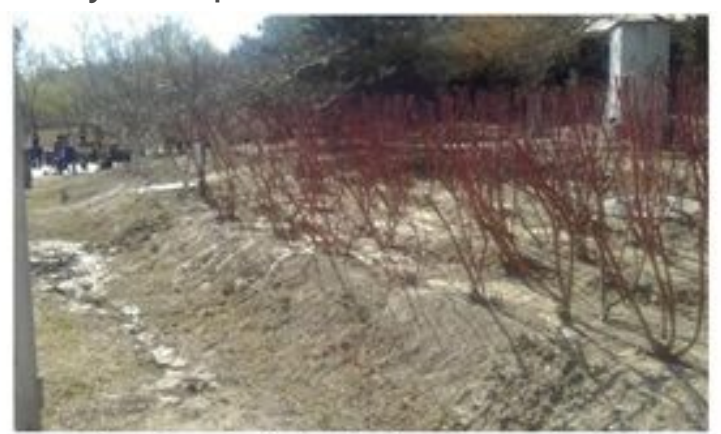

B: Regularly irrigating flower shrubs

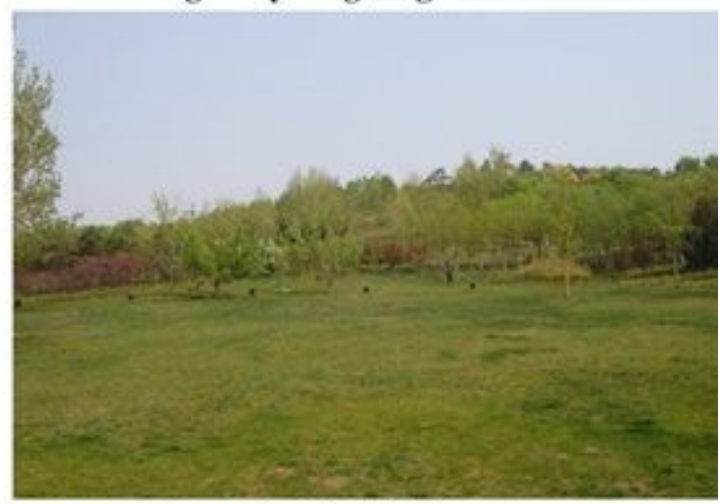

D: Turf with water

\section{Figure 5}

The landscape of well-irrigated grades $(A)$, regularly irrigating flower shrubs $(B)$, wetland covering with aquatic vegetation (C) and Turf with water (D) in BOPF . 